\title{
0 sentimento de solidão na contemporaneidade: revisitando Melanie Klein
}

\section{The feeling of loneliness in contemporaneity: revisiting Melanie Klein \\ El sentimiento de soledad en la contemporaneidad: revisitando a Melanie Klein}

\author{
Alexandre Patricio de Almeida* \\ Alfredo Naffah Neto**
}

\section{Resumo}

Este trabalho visa tecer algumas reflexões ao articular o texto "Sobre o sentimento de solidão", de autoria de Melanie Klein, com questões da contemporaneidade. Para tanto, far-se-á uma leitura detalhada deste artigo que foi publicado postumamente, em 1963. Nele, a psicanalista desenvolve um novo tópico: a existência do sentimento interno de solidão, que ela julga ser inerente a qualquer indivíduo e que compõe a sua constituição psíquica. Em seguida, os autores apresentam algumas situações contemporâneas que podem ser pensadas à luz desse paradigma kleiniano, baseando-se principalmente, na relação que se estabelece entre o sujeito e as redes sociais. As ideias de Freud sobre o Narcisismo (1914) também serão utilizadas no escopo da articulação teórica.

Palavras-chave: psicanálise, Melanie Klein, narcisismo, solidão, redes sociais.

* Universidade Paulista (UNIP). E-mail: alexandrepatriciodealmeida@yahoo.com.br

** Programa de Estudos Pós-Graduados em Psicologia Clínica, PUC-SP.E-mail: naffahneto@ gmail.com 


\section{Abstract}

This work aims reflect as it entwines the text «On the feeling of loneliness» by Melanie Klein with contemporary issues. In order to do so, a detailed reading of this article, that was, was published posthumously, in 1963, was done. In it the psychoanalist develops a new topic: the existence of the internal feeling of solitude, which she considers to be inherent in any individual and part of their psychic constitution. The authors go on to present some contemporary situations that can be thought in the light of this Kleinian paradigm, based mainly on the relationship established between the subject and social networks. Freud's ideas on Narcissism (1914) will also be referred and served as theoretical premise.

Keywords: psychoanalysis, Melanie Klein, narcissism, loneliness, social networks.

\section{Resumen}

Este trabajo busca elaborar algunas reflexiones al articular el texto "Sobre el sentimiento de soledad" de Melanie Klein con cuestiones de la contemporaneidad. Para ello, se hará una lectura detallada de este artículo que fue publicado postumamente, en 1963. En él la psicoanalista desarrolla un nuevo tópico: la existencia del sentimiento interno de soledad, que ella juzga ser inherente a cualquier individuo y compone su constitución psíquica. A continuación, los autores presentan algunas situaciones contemporáneas que pueden ser pensadas a la luz de ese paradigma kleiniano, basándose principalmente en la relación que se establece entre el sujeto y las redes sociales. Las ideas de Freud, sobre el Narcisismo (1914), también serán utilizadas en el ámbito de la articulación teórica.

Palabras clave: psicoanálisis, Melanie Klein, narcisismo, soledad, redes sociales.

\section{À GUISA DE INTRODUÇÃO}

Um texto psicanalítico sempre tem algo significativo e profundo a nos dizer, principalmente no que tange as questões existenciais. Prova disso é o quanto a leitura da obra freudiana pode se manter viva e atualizada (dada a criatividade de seu leitor e a sua capacidade de articulação). O mesmo pode ser dito das produções de grandes outros analistas. Muito do que foi escrito há décadas pode ser pensado nos dias atuais. 
Baseando-se nisso, um artigo que consideramos ser bastante relevante para refletirmos acerca das dores da contemporaneidade é o texto de Melanie Klein, publicado postumamente em 1963, com o título "Sobre o sentimento de solidão". Nesta obra, Klein nos apresenta um novo tema: o sentimento de solidão, que ela afirma ser inerente à condição da existência humana. Ela o relaciona à sua teoria do desenvolvimento psíquico e descreve que, mesmo no percurso normal, a insegurança persecutória, assim como o sentimento de culpa resultante dos processos de integração, pode produzir no sujeito uma inevitável solidão inconsciente.

Gostaríamos de lembrar que Melanie Klein não chegou a organizar este artigo para publicação, já que ela faleceu em 1960. No entanto, ela apresentou o ensaio, de forma oral, em 1959, em um Congresso em Copenhague. Presumivelmente, a própria autora não o considerava finalizado para publicar, oficialmente, em veículos científicos. No entanto, este artigo de 1963 constitui uma revisão de todo seu arcabouço teórico, deixando em evidência as ideias mais significativas de Klein ${ }^{1}$.

Além disso, o texto possui uma conotação autobiográfica, pois sabemos que, de acordo com informações a respeito de sua vida pessoal (Grosskurth, 1992; Kristeva, 2002), Melanie era uma figura solitária e com uma personalidade, digamos, bem difícil. Prova disso é a relação que teve com alguns de seus alunos e colegas, rompendo com muitos deles; era inflexível e até intolerante àqueles que questionavam a validade de suas argumentações e ideias.

Entretanto, o tema da solidão é algo que assola a nossa sociedade atual e não se restringe apenas à personalidade (e à autoria) de Melanie Klein. Uma questão controversa, diga-se de passagem, dadas as circunstâncias de facilidade de comunicação entre as pessoas, por conta das redes sociais e aplicativos de conversa. Mesmo com todos esses aparatos, a afirmação "Sinto-me muito só", ainda é ouvida com frequência nos consultórios psicanalíticos (e talvez seja por muitos anos) - fator que nos levou a realizar esta pesquisa e a nos debruçarmos sobre o artigo kleiniano.

1 Informações retiradas do item "Nota Explicativa da Comissão Editorial Inglesa", que antecede o artigo na versão de Inveja e gratidão e outros trabalhos (Klein, 1996) 
Vivemos num mundo de transformações socioculturais, políticas, morais, científicas e econômicas ocorridas na sociedade e estamos assistindo a uma significativa mudança histórica nos modos de ser e estar no mundo. Transformações que vem se engendrando há algum tempo e que, não por acaso, culminaram no desenvolvimento de novas tecnologias que refletem o modo de ser do indivíduo, ao mesmo tempo em que promovem mudanças estruturais em sua subjetividade. Hoje, as redes sociais são uma vitrine para observar a vida do outro e ser observado - o que ocorre, muitas vezes, por meio de uma dinâmica invasiva e nada saudável, que opera em níveis constitutivos do nosso $\mathrm{Eu}$. "O espaço se amplificou. Os celulares se incorporaram às nossas mãos e ao nosso cotidiano. Temos a necessidade de nos mantermos conectados e ligados. Cada vez mais é preciso se tornar visível e estar on-line" (Kallas, 2016, p. 55, itálicos nossos). Permanecer (e querer estar) sozinho é algo praticamente impossível frente a tantos estímulos externos.

Nosso artigo, portanto, visa discutir as questões da contemporaneidade que atravessam (e são atravessadas) pelo sentimento de solidão, tomando como referência o ensaio kleiniano de 1963 e o texto de Freud intitulado "Introdução ao Narcisismo", de 1914. Lançamos, assim, algumas reflexões sobre a queixa de desamparo que assola a sociedade atual. Não se pretende, de forma alguma, elaborar respostas prontas a respeito do tema levantado, mas discutir ideias fundamentais à prática (e à teoria) psicanalítica. Acerca deste tipo de pesquisa em psicanálise, citamos Dockhorn e Macedo (2015):

(...) no caso da pesquisa em psicanálise, pode-se pensar que as interpretações produzidas jamais terão o objetivo de responder permanentemente e/ou circunscrever o fenômeno estudado; na verdade, terão por objetivo ampliar o olhar e promover uma abertura para novas compreensões do fenômeno. Trata-se de interpretar o que se oferece à possibilidade de conhecimento e não de esgotá-lo ou de enunciar dogmas. (p. 531)

O que podemos pensar através das contribuições de Melanie Klein, redigidas no texto de 1963, acerca do sentimento de solidão que nos circunscreve? Por que a sociedade atual se queixa com tanta intensidade da dor 
da solidão? Em que sentido as ideias de Freud a respeito do Narcisismo podem vir a contribuir para pensarmos a constituição do Eu na contemporaneidade, tomando como referência o uso exagerado das redes sociais?

Essas questões permearão a pesquisa que fundamenta o presente artigo. Evidentemente não apresentaremos respostas formuladas e instantâneas, mas objetivamos lançar alguma luz sobre algo que nos aborda com tanta incidência e reafirma a nossa fragilidade constitucional.

\section{PERCORRENDO O TEXTO "SOBRE O SENTIMENTO DE SOLIDÃO" (1963)}

Nesta parte inicial do nosso trabalho, iremos propor algumas reflexões gerais, obtidas através da análise do artigo de Melanie Klein, "Sobre o sentimento de solidão", publicado, postumamente, em 1963. Para tanto, é imprescindível que façamos algumas breves exposições biográficas a respeito da autora, levando em consideração o momento de sua vida em que o artigo foi produzido, já que este período, em específico, fundamenta a ideia original do texto - tal como o seu propósito.

Em sua biografia publicada sobre Klein², Phyllis Grosskurth (1992) destaca, por meio de trechos selecionados de entrevistas realizadas, a vivacidade dessa psicanalista. Muitas vezes, a senhora Klein dizia à sua governanta, a Srta. Cutler: "Espero viver mais dez anos para fazer o que quero fazer" (Grosskurth, 1992, p. 483).

Aos setenta e cinco anos de idade, cercada de pessoas que a admiravam, Melanie Klein “detestava ficar só” (Grosskurth, 1992, p. 483). Certa noite, Klein entrou na cozinha de sua casa e perguntou à sua governanta se alguma vez ela já se sentira só. "Cutler respondeu que sim, mas o que procurava fazer nesses momentos de "vazio" e "solidão", era manter-se ocupada" (Grosskurth, 1992, p. 483, itálicos nossos). Refletindo alguns

2 No título original "Melanie Klein: her world and her work", publicado, originalmente, em 1986. 
instantes sobre as palavras proferidas por sua ajudante, Klein respondeu-lhe prontamente: "Sabe de uma coisa? Acho que vou escrever um artigo sobre a solidão!" (Grosskurth, 1992, p. 483).

Vale destacar, aqui, que esta ideia não fora tão impulsiva assim - como os relatos apresentados nos levam a pensar. Em 24 de julho de 1957, Winnicott apresentara à Sociedade Britânica de Psicanálise o artigo "A capacidade para estar só 3 " (no original, "The capacity to be alone"). Grosskurth (1992) comenta que estava claro que Klein havia refletido sobre o texto winnicottiano. Neste ensaio, Winnicott assinalou que, até então, pouca atenção fora dada à capacidade do sujeito em ficar só nos escritos psicanalíticos. Essa capacidade, entretanto, ele remete à experiência que o bebê tem de ficar, incialmente, só na presença da mãe. Citamos o autor:

Aqui está implícito um tipo muito especial de relação, aquela entre o lactente ou a criança pequena que está só, e a mãe substituta que está de fato confiantemente presente, ainda que representada por um momento ou por um berço ou por um carrinho de bebê, ou pela atmosfera geral do ambiente próximo. (Winnicott, 1983, p. 33)

Voltando-se para as teorias de Klein, o autor britânico supõe a existência de um objeto subjetivo que se constitui na realidade psíquica individual, resultante dos processos de cuidado obtidos por um ambiente suficientemente bom. Nesse âmbito, a diferença central do pensamento de Winnicott com o de Klein já estava demarcada, pois enquanto o autor atribuía uma enorme importância ao meio, Melanie se centrava nas questões interiores de nosso psiquismo - não iremos nos ater às diferenças epistemológicas entre esses dois autores, pois esta empreitada desviaria o objetivo deste artigo.

Na primeira manhã do Congresso de Copenhague, em 27 de julho de 1959, Klein apresentou o seu artigo "Sobre o sentimento de solidão" (Grosskurth, 1992). Trata-se de um ensaio extraordinário, profundamente delicado e, ao mesmo tempo, brilhante e comovente (Grosskurth, 1992). Para uma mulher que, até então, era demasiadamente discreta a respeito de sua própria vida, ela falou com franqueza - em prol da clareza científica 
- sobre suas experiências mais dolorosas, tais como o luto, a depressão e, obviamente, a solidão entrelaçada a tudo isso. Logo de início, deixa claro o tipo de solidão que pretendia trabalhar:

Estou me referindo ao sentimento de solidão interior - o sentimento de estar sozinho independentemente das circunstâncias externas; de se sentir só mesmo quando entre amigos ou recebendo amor. Esse estado de solidão interna, eu sugerirei, é o resultado de uma ânsia onipresente por um estado interno perfeito, inalcançável. Tal solidão que é vivenciada, em alguma medida, por todos, brota de ansiedades paranoides e depressivas que são derivados das ansiedades psicóticas do bebê. (Klein, 1996, p. 341)

Melanie Klein inicia seu texto, afirmando que o sentimento de solidão é "interior" e independe das circunstâncias externas. Diríamos, por meio de uma analogia, que a solidão brota em nós como uma semente silenciosa que cria raízes e se torna um arbusto que não pode ser arrancado. Em extremos, ela pode nos dominar por completo, gerando ansiedades e angústias (em casos patológicos); ou ser cultivada, ao ponto de possibilitar a produção de frutos (em situações saudáveis), ativando o estado criativo, por exemplo.

Para entendermos o que a autora pretende nos dizer por meio dessa afirmação, é necessário que apresentemos, resumidamente, as bases principais de sua teoria a respeito do desenvolvimento do psiquismo humano. $\mathrm{O}$ trabalho com a análise de crianças pequenas permitiu que Klein afirmasse que, desde o surgimento da vida, o ego já existe como estrutura psíquica; porém, ele é "desprovido de coesão e dominado por mecanismos de cisão" (Klein, 1996, p. 341). O perigo de ser destruído pela pulsão de morte (que na concepção kleiniana é inata e constitucional) dirigida ao próprio self obriga o nosso psiquismo a ativar o mecanismo de cisão como defesa, dividindo os impulsos em bons e maus. Devido à projeção desses impulsos sobre o primeiro objeto externo, este também será, inevitavelmente, cindido em bom e mau.

A autora, portanto, propõe que os mecanismos de projeção e introjeção são os vértices que sustentam o nosso psiquismo - tais como os movimentos de inspirar e expirar são cruciais à nossa sobrevivência. O trecho a seguir, citado do livro "Vida Interior", de Margot Waddell (2017), aborda esses processos de maneira didática e coerente. Vejamos: 
O bebê inicialmente relaciona-se com o mundo, e o coloca para dentro, através da sua experiência com sua mãe. [...] Quando um bebê está com raiva, ele fica totalmente com raiva. Com todo seu ser, ele percebe sua mãe como a fonte da sua dor e raiva. Ele se sente mau. Quer se livrar desse sentimento. Ele o empurra de volta à sua suposta fonte, ou seja, a mãe. Aos seus olhos, sua própria mãe se torna má. Ele tem uma mãe má dentro dele. Quando ela o conforta e alimenta, e ele tem um sentimento bom, sua mãe volta a ser boa. Ele "projeta" seu sentimento bom e os identifica com ela. Ele "introjeta” sua experiência com ela como sendo calma, satisfatória e boa; ele próprio adquire um sentimento bom dentro dele. Ele sente que ele é "bom". (Waddell, 2017, p. 362)

"Junto com a necessidade de cindir, existe desde o início da vida uma tendência à integração, que aumenta com o crescimento do ego" (Klein, 1996, p. 341). A integração seria, portanto, o resultado da introjeção do objeto bom. É a partir disso que os mecanismos de cisão irão abrir espaço para a consolidação do ego e a expansão das relações objetais. "Uma relação inicial satisfatória com a mãe implica um contato íntimo entre o inconsciente da mãe e o da criança” (Klein, 1996, p. 342, itálicos nossos). Porém, sempre que os impulsos agressivos surgirem com uma maior intensidade, a mãe e o seio também serão sentidos como persecutórios (devido à projeção e à introjeção), e por isso o bebê sentirá uma insegurança enorme (ficando à deriva de um objeto que não veio a se integrar). Isso implicará num sentimento de solidão desesperador.

"Mesmo na melhor das hipóteses, no entanto, a relação feliz com a mãe e seu seio nunca é livre de perturbações" (Klein, 1996, p. 342, itálicos nossos). A integração plena nunca é totalmente alcançada ${ }^{4}$. Posto isso, a compreensão absoluta de nossas emoções torna-se uma tarefa impossível de se realizar. Klein dirá que o anseio de compreender a si próprio também está ligado à necessidade de ser compreendido pelo bom objeto internalizado.

Uma expressão desse anseio é a fantasia universal de se ter um gêmeo - uma fantasia para a qual Bion chamou a atenção, num artigo não publicado. Essa figura gêmea, como ele sugeriu, representa aquelas partes não compreendidas

4 Lembremos que o desenvolvimento psíquico, para Klein, não é linear, como tampouco segue o modelo de fases - como propôs Freud. Ela apresentou a concepção de "posições" esquizoparanoide e depressiva - que oscilam durante toda a vida do sujeito (Klein, 1946). 
e excindidas que o indivíduo anseia por recuperar, na esperança de alcançar a inteireza e completa compreensão; essas partes são algumas vezes, sentidas como sendo as partes ideais. (Klein, 1996, p. 343)

Não fica difícil de entender essa analogia de Bion quando pensamos que muitas pessoas que conhecemos buscam a sua "alma gêmea" como única condição para serem felizes (e completas). Numa linguagem kleiniana, diríamos que essas pessoas buscam suas partes cindidas, no desejo de serem elaboradas por um "suposto" objeto bom externo, já que elas não as tiveram originalmente e não puderam elaborar as suas angústias. Temos, com isso, a procura implacável por um "pedaço" que lhe complete. Uma grande ilusão da existência, na verdade, pois, como afirmara Klein, “a integração plena é impossível" (Klein, 1996, p. 342).

Outro conceito fundamental de sua obra, que Klein retoma neste texto de 1963, é o de identificação projetiva. Este mecanismo de defesa é baseado na cisão do ego e na projeção de partes do self para dentro de outras pessoas. Caper (1990) nos dirá que "com o termo identificação projetiva, Klein descreveu um tipo de identificação no qual a experiência do sujeito em relação à natureza do objeto é alterada de forma relevante pelas projeções do sujeito antes ou durante o processo de introjeção" (Caper, 1990, p. 186, itálicos do autor). E complementa:

A identificação projetiva funciona em dois níveis. O primeiro é o nível da fantasia inconsciente que viemos considerando. O segundo também é inconsciente, mas "realista". Nesse nível, o sujeito age de várias maneiras para moldar a realidade externa, de forma que se ajuste melhor ao que, na fantasia, foi nela projetado. (Caper, 1990, p. 187)

Nesse mecanismo de defesa, partes do eu (self) e dos objetos internos são expelidos (split off) e projetados no objeto externo, o qual então se torna possuído e controlado pelas partes projetadas, identificando-se com elas (Segal, 1975). Ela pode ser dirigida ao objeto bom, a fim de evitar a separação, como também ao objeto mau (persecutório), a fim de obter o controle sobre a fonte de ameaças ao ego. A identificação projetiva tem início quando se estabelece a posição esquizoparanoide, mas persiste e, em geral, se intensifica quando a mãe é percebida como um objeto total, podendo 
ocorrer com outros objetos externos durante toda a vida do sujeito. Quanto mais o indivíduo se utiliza deste mecanismo de defesa, mais o seu ego é empobrecido, devido às múltiplas cisões realizadas e projetadas ao externo para obter o controle daquilo que foge ao seu domínio.

O esquizofrênico, por exemplo, sente que está despedaçado e nunca terá posse de seu self(Klein, 1996). Ele não pode confiar num objeto bom, assim como não pode confiar em si mesmo. Seu ego está desmantelado por tantos mecanismos de cisão e pelo uso excessivo de identificações projetivas - seu mundo interior está fragmentado e enfraquecido. Para Klein, este fator também estará vinculado à solidão, pois aumenta o sentimento do esquizofrênico de que foi deixado a sós, abandonado com sua “desgraça”, já que não teve um objeto bom forte o suficiente em que acreditar. Nas palavras da autora: "o sentimento de estar rodeado por um mundo hostil, que é característico do aspecto paranoide da doença esquizofrênica, não apenas aumenta suas ansiedades, como influencia vitalmente os seus sentimentos de solidão" (Klein, 1996, p. 345).

Outro fator que implica no penoso sentimento de solidão do esquizofrênico seria, para Melanie Klein, o seu estado de “confusão", propício do uso recorrente de diversos mecanismos de defesa - como a identificação projetiva e a cisão do ego. Esses fatores, agregados à sua desconfiança paranoide sobre os outros, "resultam num estado de desligamento que destrói sua habilidade para estabelecer relações de objeto e obter delas o reasseguramento e o prazer que poderiam contrabalançar a solidão" (Klein, 1996, p. 345, itálicos nossos).

Diferente do que ocorre na posição esquizoparanoide, na posição depressiva temos o reconhecimento da integridade do objeto; portanto, o que antes estava cindido em bom e mal, passa a ser reconhecido como uma unidade (um único objeto). O bebê se dá conta de que a mãe odiada e a mãe amada são a "mesma pessoa". Com isso, advém o sentimento de culpa, ou seja, o sujeito se sente culpado por ter odiado e despejado suas projeções aniquiladoras sobre o mesmo objeto que o alimenta e o satisfaz. Deste impasse, Klein retira o nome "posição depressiva”, justificada pela 
“depressão ${ }^{5}$ ” surgida pela culpa. Nesta estrutura psíquica é possível perceber-se como um objeto total (amando e odiando, possuindo qualidades e defeitos); além de perceber-se em relações de objeto também totais e que, por isso, satisfazem e frustram. Tal mudança no psiquismo possibilita ao indivíduo acompanhar a continuidade da experiência de si mesmo e do outro. Este modo de viver amplia o conhecimento de mundo e de si, mas não deixa o bebê livre de novas ansiedades.

Como aceitar em mim aspectos tão agressivos e repugnantes que, em algum momento, foram responsáveis por colocar em risco a relação com as pessoas que eu amo? Como conciliar o fato de que o objeto que eu amo é também aquele que já odiei? Essas questões são a origem da intensa angústia do sujeito na posição depressiva. Com o sentimento de unidade, o bebê é assolado por ter que se deparar consigo mesmo e assumir as suas responsabilidades afetivas. Defrontar-se com si próprio é uma tarefa árdua e que gera bastante solidão (é como se olhar no espelho, procurando algum tipo de amparo). Sobre este aspecto, Klein ainda irá nos dizer que:

[...] a dor que acompanha os processos de integração também contribui para a solidão, pois significa fazer face aos próprios impulsos destrutivos e partes odiadas do self, que, por vezes, parecem ser incontroláveis e que, desse modo, colocam em perigo o objeto bom. Com a integração e um sentimento crescente de realidade, a onipotência certamente enfraquecerá, e isso uma vez mais contribui para a dor da integração, pois significa uma capacidade diminuída de ter esperança. (Klein, 1996, p. 345)

Nas palavras da autora: "já ouvi pacientes expressarem a dor da integração em termos de se sentirem sós e abandonados, por estarem completamente sozinhos com aquilo que, para eles, era uma parte má do self' (Klein, 1996, p. 343). Por esta via, Klein nos remete a um abismo sem fim: todas as estruturas psíquicas (das mais saudáveis às patológicas) nos atiram ao precipício da solidão. Então, o que nos resta fazer?

Aqui, faremos um breve intervalo na discussão do artigo kleiniano de 1963 para, então, retomá-lo nas considerações finais, enlaçando as

5 Não utilizada, aqui, em seu sentido patológico. 
questões levantadas a seguir acerca da "solidão e a contemporaneidade" aos fundamentos teóricos apresentados por Melanie Klein ao longo de seu texto sobre o sentimento de solidão.

\section{REDES SOCIAIS: SOLIDÃO E CONTEMPORANEIDADE}

Se o mercado é o grande organizador da vida social, os valores excludentes da vida privada sobrepõem-se aos valores que organizam o espaço público. Ser bom pai/boa mãe não significa "transmitir o melhor" para os filhos, e sim "dar tudo de bom" aos rebentos, ao que acrescenta automaticamente: "eles merecem". O mérito não é uma conquista, é um direito (prévio) do consumidor. (Kehl, 2015, p. 284)

“Consuma! Não sofra! Seja feliz! Ostente!” Estas palavras parecem ser o grito de guerra de nossa sociedade atual. Uma sociedade que preza a imposição da satisfação sobre todas as outras coisas. Chorar virou sinal de fraqueza. Demonstrar isso publicamente é uma atitude muito pior. Para atestarmos isso, basta percorrer o feed de redes sociais como o Facebook e, principalmente, o Instagram. Lidar com a solidão que nos atinge parece algo não permitido. O tempo todo, as pessoas mantêm um status de falsa realização. A busca desesperada por likes já não é uma razão para nos espantarmos, dentro desse paradigma. O problema é: a cicatriz da solidão que nos marca permanentemente está sendo preenchida por esses meios?

Analisando alguns dados estatísticos, fica evidente que não. Como descreve Maria Rita Kehl em seu livro “O tempo e o cão” (2015):

A depressão nos Estados Unidos é a principal causa da incapacitação em pessoas acima de cinco anos de idade. Estima-se que $15 \%$ das pessoas deprimidas cometerão suicídios. Os suicídios entre jovens e crianças de dez a quatorze anos aumentaram 120\% entre 1980 e 1990 (Kehl, 2015, p. 50).

Dados mais recentes demonstram que a depressão afeta 322 milhões de pessoas no mundo, segundo resultados divulgados pela Organização Mundial de Saúde (OMS), referentes ao ano de 2015. Em 10 anos, de 2005 a 2015, esse número cresceu para elevados $18,4 \%$. A prevalência do transtorno depressivo na população mundial é de 4,4\%. Já no Brasil, 5,8\% da 
população sofre com esse problema, que já afeta 11,5 milhões de brasileiros (G1, 2017). Segundo essa mesma pesquisa, realizada pela OMS, o Brasil é o país com maior prevalência de depressão da América Latina e o segundo com maior prevalência nas Américas, ficando atrás somente dos Estados Unidos, que possuem 5,9\% de depressivos em seu contingente populacional.

A ilusão de achar que os likes das fotos poderão completar uma lacuna que nos é inerente acaba caindo por terra alguma hora e o desespero angustiante que emerge desse ocorrido é sufocador. Por mais que você publique uma foto nova, com uma nova roupa ou uma viagem excêntrica (e cara), a sensação de vazio permanece ali. Esse buraco continua nos ocupando e ampliando ("nos bastidores" da vida psíquica) uma ferida que jamais se fecha.

Concomitante a isso, temos a busca de uma identificação construída pela imagem a qual transmitimos: precisamos do olhar do outro para existir e como consequência, haverá sempre a necessidade desse outro para nos edificar. Daí a solidão se torna ainda mais insuportável. "As pessoas postam em redes sociais o que consideram o melhor de si, assim como são capazes de expressar, em perfis falsos ou não, o lado mais preconceituoso e agressivo de seu ser" (Kallas, 2016, p. 56). Temos, então, uma personalidade construída, ilusoriamente, a partir da suposição (imagética) do outro, e uma manifestação da agressividade sem limites, mas censurada (e protegida) pelo véu encobridor do mundo virtual (Kallas, 2016).

A utilização compulsiva das redes sociais para o preenchimento do tempo livre também merece ser discutida, nesse âmbito. Naqueles intervalos em que poderíamos estar "cara a cara" com a nossa subjetividade, reconhecendo as nossas fraquezas e admirando as nossas virtudes, recorremos ao celular para nos entreter com assuntos que possuem a falsa impressão de nos completar. Nesse instante também buscamos a ajuda do outro, "um outro virtual” é claro, mas que pode nos retirar (ilusoriamente) da angústia e do silêncio desesperador da solidão.

Sobre essa questão, Dunker (2017) nos dirá:

Sabemos que precisamos de solidão quando nos sentimos vazios ou isolados. As patologias da solidão apontam que estamos em falta com a verdadeira solidão. A coisa se torna venenosa, porque nossa primeira reação é combater 
esses estados de isolamento e o vazio com "falsas experiências de solidão" ou com "próteses de experiências de reconhecimento", às vezes com festas, outras pelo engajamento em conversas ou relações "vazias". (p. 33)

A possibilidade de instantaneamente acessar qualquer coisa e obter a satisfação, mesmo em fantasia, de nossos impulsos sexuais; a nossa competitividade, explícita através dos jogos em rede; matar a sede de nossa curiosidade intelectual; ou simplesmente dar um "clique" e admirar os nossos anseios se tornando "realidade" reduz o limiar a ser atravessado entre o impulso e o desejo e a ação. "O tempo entre escolher e clicar é muito curto e a gratificação é imediata” (Kallas, 2016, p. 56). Sendo assim, “a necessidade de esperar e/ou modular o nosso desejo está ausente quando utilizamos a internet. Aí reside um de seus maiores perigos, o que pode transformar o seu uso em abusivo ou viciante" (Kallas, 2016, p. 56).

Hoje já é comum ouvirmos o termo "dependência de internet" como uma das principais queixas clínicas a ser abordada, ao lado de outros tipos de dependência (Greenfield, 2011). Satisfazer o desejo imediatamente nos impossibilita pensar em nossas próprias limitações, na mesma medida em que impede a reflexão a respeito de nossa essência psíquica (e subjetiva), pois, como já dito, a completude perfeita é falsa e ilusória. Anulamo-nos diante do olhar do outro, assim como nos perdemos na voracidade de nossos desejos. Estamos vivendo, desse modo, buscando permanentemente a fuga do vazio e lutando bravamente contra o isolamento. A benéfica importância da solidão tomou o rumo de um significado negativo e ruim. "Toda a vez que estou sem alguém, tento me preencher de algo", pensa o sujeito de hoje. Pensamento este que se manifesta pelas queixas de nossos pacientes.

\section{SOLIDÃO E NARCISISMO}

"Klein afastou-se radicalmente de Freud a respeito da natureza do narcisismo" (Hinshelwood, 1992, p. 374). No entanto, apesar de a autora não abordar, diretamente, em seus textos o termo "narcisismo", ela se refere de modo indireto às ideias de Freud. Tentaremos, a seguir, discutir alguns princípios que permeiam a noção de narcisismo, intercalando-os às 
ideias kleinianas, a fim de enriquecermos, ainda mais, a discussão subjetiva acerca do intenso sentimento de solidão do qual se queixa o sujeito na contemporaneidade.

Ao nos debruçarmos sobre o artigo de Freud de 1914 - "Introdução ao Narcisismo" -, nos damos conta, após uma leitura crítica e reflexiva, que os momentos de transformação, evolução e progresso psíquico são aqueles que, geralmente, foram precedidos por pequenos períodos de isolamento, onde a libido é retirada do mundo externo e volta-se ao Eu, sendo a base constitutiva do amor próprio e do autoconhecimento indispensável à maturação (Freud, 2010). Não nos referimos, aqui, ao egoísmo infantil que limita (e restringe) as relações objetais, mas ao retorno de um estado primário, constitutivo e essencial para garantir as bases saudáveis da personalidade e a segurança de acreditar em si. Até porque Freud dirá, nesse mesmo artigo, que "é preciso amar, para não adoecer" (Freud, 2010, p. 29, itálicos nossos).

A capacidade de estar só está ligada ao conceito de autoestima - e nesse aspecto o amor próprio é essencial, como já fora dito. Por outro lado, só teremos amor próprio se tivermos desenvolvido a aptidão de fruir o objeto bom e nos sentirmos gratificados por ele (aqui, fazemos alusão ao texto kleiniano). São esses os pilares que irão sustentar a nossa segurança psíquica e a envergadura para lidar com o nosso "vazio interior", já que sempre carregaremos algo suficientemente bom em nossa constituição interna e, dessa forma, jamais estaremos realmente sozinhos.

Freud dirá, neste mesmo texto, que "o narcisismo de uma pessoa tem grande fascínio para aquelas que desistiram da dimensão plena de seu próprio narcisismo" (Freud, 2010, p. 34). Ou seja, tendemos a admirar quem possui autoconfiança para levar a vida de bem consigo próprio. Uma admiração que, às vezes, se manifesta pela inveja ou desdém daqueles que são incapazes de se recolherem para mergulhar nos mares profundos de sua vasta imensidão subjetiva. Nesse sentido, uma solidão que possibilita crescimento pode ser ilustrada pela famosa expressão "preciso de um tempo para mim”. Procurar o isolamento pode ser uma forma de deixar a voz e o olhar do outro (que estão dentro de nós) esvaziarem-se. Com essa atitude, buscamos o encontro de nossa própria voz, nos olhamos "de dentro". Esse 
movimento é o primeiro passo para descobrir o desconhecido que nos habita e que, por muitas vezes, foi perdido ou descontruído pelo olhar dilacerante e exigente que vem do outro (seja real ou virtual).

Voltando ao texto de Freud, ele afirma que "os pais são levados a atribuir à criança todas as perfeições - que um observador neutro nelas não encontraria - e ocultar e esquecer todos os defeitos" (Freud, 2010, p. 36). Nesse processo de proteção e cuidado temos a base constitutiva de segurança do $\mathrm{Eu}$, apoiada na lembrança de um dia ter sido desejado (e admirado) em todo nosso estado pleno de "perfeição". "As coisas devem ser melhores para a criança do que foram para os seus pais, ela não deve estar sujeita às necessidades que reconhecemos como dominantes na vida" (Freud, 2010, p. 36). Os pais, temerosos pela vida do filho, prezam por ele, tendo a preocupação de oferecer-lhes uma perspectiva melhor de futuro (e de presente). "His Majesty the Baby, como um dia pensamos de nós mesmos" (Freud, 2010, p. 36). O bebê é o centro das atenções e, ao mesmo tempo, "não é outra coisa senão o narcisismo dos pais renascido, que, na sua transformação de amor objetal, revela inconfundivelmente a sua natureza de outrora" (Freud, 2010, p. 36).

Em contrapartida, o sujeito que não recebeu esse amor (investimento libidinal) dos pais no início da vida carregará uma fenda em sua existência - o que alguns autores denominaram de "ferida narcísica". Este indivíduo nunca ocupou o lugar de "vossa majestade, o bebê"; portanto, o seu Eu não foi fortificado o suficiente. Trata-se de um Eu frágil, que busca se estruturar a partir de alguém que seja mais forte que ele. Um "prato cheio" para ser devorado pelas influências estereotipadas determinadas duramente pelas redes sociais. "Só serei alguém se me adequar a este modelo" pensa o pobre indivíduo portador desta ferida.

Desse modo, o conceito de narcisismo se expande e ganha outras formas. No entanto, ainda é, infelizmente, bastante comum ouvirmos nos corredores psicanalíticos que alguém narcisista é alguém que não se preocupa com o outro. Porém, caminhando com a discussão que fizemos até este ponto, percebemos que o termo não possui apenas essa conotação conceitual pejorativa, ou seja, um pouco de narcisismo é necessário e, porque não, vital ao nosso psiquismo. "Considerar o narcisismo um conceito plural não só 
respeita a especificidade das diferentes redes conceituais com as quais se articula, assim como também evita recorrer a artifícios” (Miguelez, 2015, p. 16) reducionistas e simplificadores. Ampliando a discussão, o autor ainda nos dirá que:

O enlace do narcisismo com a incorporação, a introjeção e, finalmente, a identificação, permite articulações que esclarecem sua participação na tópica - eu-ideal, ideal do eu - e enriquecem a compreensão do aparelho psíquico - esses primeiros momentos em que dentro/fora, eu/não eu, eu/ outro, mental/corporal não possuem fronteiras demarcadas com clareza. (Miguelez, 2015, p. 15)

Nesse aspecto, relacionando os princípios defendidos por Freud e Klein, percebemos que quanto mais o Eu do sujeito for "encorpado" por seu narcisismo primário - pelos pilares que sustentam o seu Eu ideal -, mais a sua personalidade estará integrada, com a esperança de que algo bom e seguro estará dentro de si, processo, este, que tende a diminuir o estado de vulnerabilidade ao olhar estruturante e, por conseguinte, dependente de "outro externo".

Melanie Klein (1996), por sua vez, nos dirá que, quanto mais implacável o Superego, maior será a solidão, pois as exigências severas aumentam as ansiedades depressivas e persecutórias. Assim, um Eu frágil tende a se deixar dominar pela demanda externa e interna - resultante de um Superego tirânico. Nesse aspecto, observa-se novamente uma relação com as questões atuais e as exigências sociais impostas para estar em evidência: deve-se ser bonito, magro, culto, divertido, inteligente, moderno, eficaz etc. Muitas coisas ao mesmo tempo, e ao sujeito torna-se impossível sustentar essas imposições. Esse mesmo sujeito será assolado pela solidão e com isso buscará o preenchimento ilusório obtido pelas redes sociais - temos igualmente, um labirinto onde a saída se torna, praticamente, impossível.

O que é importante considerar, de fato, após estas breves discussões teóricas, é que, durante toda a nossa jornada existencial, seremos acometidos por acontecimentos que irão intensificar o nosso sentimento interno de perda e solidão, como por exemplo: 
Perder a "mordomia" da primeira infância, o colo, a mamadeira, a atenção, os mimos, as fraldas, a presença constante dos adultos que ficam em volta das crianças menores. A entrada e a saída de escolas, mudança de casas, cidades, separação dos pais, perda de amigos. As crianças deixam para trás seus mais queridos brinquedos, livros, roupas, adoecem, curam-se, mudam de corpo, de voz. Mas todas essas perdas são oportunidades, e a análise kleiniana está voltada para nos libertar de uma forma de dor que bloqueia o acesso às novas oportunidades de vida. (Cintra, 2007, p. 316)

Através desse recorte do texto de Cintra (2007) percebemos o quanto Klein nos ensinou a lidar com os nossos próprios fantasmas. Esta original autora da psicanálise nos mostra, por meio de suas acepções clínicas e conjecturas teóricas que, por mais que enfrentemos perdas na vida, o que produzirá o nosso engrandecimento será a capacidade de nos depararmos com o nosso inerente vazio, sem buscar recursos ilusórios de preenchimento que nos afastam de nossa verdadeira essência e nos deixam à deriva de nosso próprio (e verdadeiro) Eu.

\section{CONSIDERAÇÕES FINAIS}

Uma das grandes críticas à obra kleiniana é que ela deu enorme relevância aos aspectos internos do sujeito, desconsiderando os aspectos externos (o ambiente). Pensamos que isso não seja totalmente verdade. Ao falar de um objeto interno bom, Klein atribui importância indireta a um ambiente acolhedor e facilitador, onde existam condições de cuidado necessárias para uma constituição psíquica saudável - só haverá a introjeção de um bom objeto se o ambiente oferecer cuidado e estiver disponível ao bebê. Deste modo, um meio estável e equilibrado dará subsídios para que o indivíduo tenha mais condições de vir a ter um baluarte interno psíquico para lidar com as dores de sua solidão.

Analisando o comparativo que propusemos da teoria kleiniana com a noção metapsicológica de Freud (2010) acerca do Narcisismo, é possível entender que o sujeito que possui em sua constituição psíquica uma ferida narcísica, que impede o seu Eu de se fortalecer, buscará a aprovação do meio para existir (e se construir). Nesse sentido, o sentimento de solidão 
constitucional será sempre falsamente preenchido por defesas de estar com e ser como alguém - o que produz uma lacuna imensa no sentido existencial (e subjetivo).

Melanie Klein, por sua vez, nos dirá que "embora a solidão possa ser minorada ou aumentada por influências externas, nunca poderá ser completamente eliminada" (Klein, 1996, p. 354). Portanto, é inevitável que nos sintamos sozinhos durante muitos momentos da vida. O que nos impede de adoecer é a habilidade de lidar com esse sentimento, utilizando-o para a nossa própria evolução pessoal. É aqui que nos enxergamos, mas sem precisar de um espelho. Vemo-nos sob o nosso olhar mais profundo e delicado, aquele olhar que engrandece e nos dá liberdade. Um olhar que desperta o que há de mais criativo em nosso $\mathrm{Eu}$, mas que estava adormecido ou soterrado pela constância de estímulos superficiais.

Não se trata de descaso com o próximo, ou do isolamento proposital como defesa maníaca (como já destacamos), mas a procura de uma identidade constituída pelo "corte do laço”, pois, ao aprendermos a cuidar de nós mesmo, também aprendemos a cuidar dos outros. É a inclinação de estar de bem consigo mesmo - ponto basilar defendido por Freud, no texto de 1914, ao afirmar que o narcisismo de alguém desperta fascínio naquele que abdicou de seu próprio narcisismo.

"Finalmente, se voltamos o olhar para o pensamento kleiniano, talvez a primeira coisa que chame nossa atenção em seu trabalho clínico seja o seu jeito de prestar atenção e manter-se próxima à experiência de sofrimento e ansiedade dos pacientes" (Cintra, 2007, p. 316). Ansiedades essas que, em níveis muito intensos, perturbam o nosso potencial criativo e impedem o progresso psíquico - como ocorre nas redes sociais, ao se usar o modelo do outro como único exemplo a ser seguido. Baseando-se em fotos de pessoas sempre felizes e supostamente realizadas, o indivíduo toma como parâmetro de vida um ideal de felicidade e completude que, de fato, não existe.

Ora, por essa via compreendemos, portanto, o que queremos demonstrar com a escrita deste trabalho. Klein irá, justamente, nos dizer que o sentimento de solidão é interno e inerente à nossa existência, o que gera um grande paradoxo perante as questões contemporâneas referentes às influências externas. Logo, temos a seguinte equação: quanto mais eu me 
anulo, tomando como parâmetro o ideal imaginário imposto pelas exigências predominantes nas redes sociais, mais me afasto do profundo (e significante) contato que deve existir com o meu verdadeiro Eu. Ele irá permitir a descoberta de nossas reais vulnerabilidades, de nossos potenciais, assim como de nossas próprias limitações; capacidades, essas, que são advindas da aptidão de estar só e de lidar de modo maduro com a autêntica solidão que nos invade, mesmo estando cercado de tantos estímulos.

Um bom tratamento psicanalítico permite ao indivíduo que ele estruture os seus processos de simbolização - algo muito defendido por Melanie Klein. Ao nos valermos desse mecanismo somos capazes de transformar as nossas ansiedades mais arcaicas (de controle e perseguição), nos emancipando de exemplos já estabelecidos e fixados em nossas raízes (como a imagem idealizada dos pais, dos mestres, e dos padrões, por exemplo). É saber que estamos a sós, sem nos desesperar com o encontro dessa solidão. Admitir a nossa condição de "abandono" pode ser o primeiro passo para a independência (Cintra, 2007).

Voltemos, por fim, ao artigo de Melanie Klein (1996). Em sua parte final, a autora dirá que "alguns bebês se utilizam de uma extrema dependência à mãe como uma defesa contra a solidão, e a necessidade de dependência permanece como um padrão por toda a vida" (Klein, 1996, p. 352). Novamente caminhamos ao encontro das ideias freudianas a respeito do narcisismo primário, pois o sujeito que não recebeu os devidos cuidados e investimentos amorosos de seus pais (ou do meio) portará consigo uma falha constitutiva atrelada ao desamparo, estando mais suscetível às influências tirânicas das redes sociais - buscando uma necessidade de preenchimento constante, o que o afastará de seu verdadeiro ser.

Klein ainda nos dirá que “a negação da solidão, que com frequência é usada como uma defesa, provavelmente atrapalhará boas relações de objeto, em contraste com uma atitude na qual a solidão é realmente vivenciada" (Klein, 1996, p. 352, itálicos nossos). Nesse âmbito, as artes, em geral, viajar, escrever, compor, ler algo interessante, ou até mesmo ficar no quarto ouvindo músicas por horas, são alguns exemplos de alternativas em que 
podemos nos encontrar com nós mesmos. Um engrandecimento da alma que apenas a maturidade (e alguns anos de análise) pode proporcionar para quem não consegue ver o lado bom de estar sozinho.

Um percurso doloroso, mas necessário. E, com o aumento da disposição de ficar só, pode se tornar muito gratificante. Ao desfrutar de nossa própria companhia perceberemos, enfim, que as redes sociais estão lá para serem usufruídas, mas, de forma alguma, devemos permitir sermos usufruídos por elas. Mesmo porque a dor da existência nos seguirá durante toda a vida e o engrandecimento gerado pela gratidão de estar só (consigo próprio) será uma recompensa que apenas cada um poderá, quiçá um dia, encontrar dentro de si.

\section{REFERÊNCIAS}

Caper, R. (1990). Fatos imateriais: a descoberta de Freud da realidade psíquica e o desenvolvimento kleiniano do trabalho de Freud. Rio de Janeiro: Imago.

Cintra, E. M. U. (2007). Pensar as feridas. In M. C. Pinto (Org) Livro de ouro da psicanálise (pp. 307-317). Rio de Janeiro: Ediouro.

Dockhorn, C. N. B., \& Macedo, M. M. K. (2015). Estratégia Clínicointerpretativa: um recurso à pesquisa psicanalítica. Psicologia: Teoria e Pesquisa, 31(4), 529-535.

Dunker, C. (2017). Reinvenção da intimidade - políticas do sofrimento cotidiano. São Paulo: Ubu Editora.

Freud, S. (2010). Introdução ao narcisismo. In S. Freud, Obras Completas, volume 12 (pp. 13-50). Trad. Paulo César de Souza. São Paulo: Companhia das Letras.

G1 (2017). Depressão cresce no mundo, segundo OMS; Brasil tem maior prevalência da América Latina. Recuperado de https://g1.globo. com/bemestar/noticia/depressao-cresce-no-mundo-segundo-omsbrasil-tem-maior-prevalencia-da-america-latina.ghtml Acesso em $30 \mathrm{Jul} 2018$.

Greenfield, D. (2011). Dependência de internet: manual e guia de avaliação e tratamento. Porto Alegre: Artmed. 
Grosskurth, P. (1992). O Mundo e a obra de Melanie Klein. Rio de Janeiro: Imago.

Hinshelwood, R. D. (1992). Dicionário do pensamento kleiniano. Porto Alegre: Artes Médicas.

Kallas, M. B. L. M. (2016). O sujeito contemporâneo, o mundo virtual e a psicanálise. Reverso, 38(71), 55-64.

Kehl, M. R. (2015) O tempo e o cão: a atualidade das depressões. 2. Ed. São Paulo: Boitempo.

Klein, M. (1996). Sobre o sentimento de solidão. In M. Klein, Inveja e gratidão e outros trabalhos (1946-1963) (pp. 340-354). Rio de Janeiro: Imago.

Kristeva, J. (2002) O gênio feminino. Tomo II: Melanie Klein. Rio de Janeiro: Rocco.

Miguelez, O. M. (2015). Narcisismos. 2. Ed. São Paulo: Escuta.

Segal, A. (1975). Introdução à obra de Melanie Klein. Rio de Janeiro: Imago. Waddell, M. (2017). Vida interior: psicanálise e desenvolvimento da personalidade. São Paulo: Blucher.

Winnicott, W. (1983). A capacidade para estar só. In D. W. Winnicott, $O$ ambiente e os processos de maturação: estudos sobre a teoria do desenvolvimento emocional (pp. 31-37). Trad. Irineo Constantino Schuch Ortiz. Porto Alegre: Artmed.

Recebido em 21/08/2018 Aceito em 09/09/2019 